\title{
NUTRITIONAL, PHYSICAL, PSYCHOSOCIAL, AND COMMORBID DISEASE AFFECTING QUALITY OF LIFE IN KNEE OSTEOARTRITIS PATIENTS AT WILLIAM BOOTH HOSPITAL, SEMARANG
}

\author{
Hari Peni Julianti, Dea Amarilisa Adespin, \\ Trilaksana Nugroho, Nur Laelatul Rasyidin \\ Faculty of Medicine, Universitas Diponegoro
}

\begin{abstract}
Background: Osteoarthritis (OA), especially knee OA, is the fourth cause of disability in the world. OA affected the daily physical activity and quality of life of the patients. This study aimed to analyze the various factors that affect nutritional, physical, psychosocial, and comorbid disease affecting quality of life in knee osteoarthritis patients at William Booth hospital, Semarang, Central Java.

Subjects and Method: This was a cross-sectional study conducted at William Booth Hospital, Semarang, Central Java. A sample of 79 patients with knee osteoarthritis was selected by simple random sampling. The dependent variable was the quality of life. The independent variables were age, nutritional status, pain intensity, radiological features, family function, length of illness, unilateral/ bilateral OA knee, hypertension, and diabetes mellitus. The data were analyzed by chi-square.

Results: Osteoarthritis in elderlies was significantly associated with age $(p<0.001)$, nutritional status ( $\mathrm{p}<0.001)$, pain intensity $(\mathrm{p}<0.001)$, radiological features $(\mathrm{p}=0.020)$, and family function ( $\mathrm{p}<0.001)$. Osteoarthritis in elderlies was insignificantly associated with length of illness $(p=0.445)$, unilateral/ bilateral OA knee $(p=0.153)$, hypertension $(p=0.272)$, and diabetes mellitus $(\mathrm{p}=0.617)$.

Conclusion: Osteoarthritis in elderlies is significantly associated with age, nutritional status, pain intensity, radiological features, and family function, but insignificantly associated with length of illness, unilateral/ bilateral OA knee, hypertension, and diabetes mellitus.
\end{abstract}

Keywords: elderly, osteoarthritis, quality of life

\section{Correspondence:}

Hari Peni Julianti. Faculty of Medicine, Universitas Diponegoro. Jl. Prof Sudarto SH, Tembalang, Semarang, Central Java. Email: hari_peni@yahoo.com. Mobile: +62813263-81347. 